\title{
HEMODYNAMIC ALTERATIONS DUE TO SALMONELLA TYPHOSA ENDOTOXIN WITH SPECIAL REFERENCE TO THE CORONARY VASCULAR BED *
}

\author{
By EDWARD D. FROHLICH, JERRY B. SCOTT AND ELMO S. DOOLEY with the \\ TECHNICAL ASSISTANCE OF MIGUEL RAMIREZ AND CARL C. HICKS
}

\author{
(From the Environmental Medicine Division, U. S. Army Medical Research Laboratory, \\ Fort Knox, Ky.)
}

(Submitted for publication May 22, 1961 ; accepted August 31, 1961)

The general physiological and more detailed hemodynamic alterations produced in animals by bacterial endotoxins have been reviewed by Thomas (1) and Gilbert (2). It has been shown that after the administration of endotoxin there is a fall in cardiac output which is accompanied by a decrease in auricular filling. Despite the extensive literature on the hemodynamic effects produced by endotoxin in various vascular beds, little attention has been given to the study of its action on the coronary circulation.

In Gilbert's review (2), it was held that there was "no evidence to date to support the view that endotoxin had any important effect on myocardial function." More recently, however, Maxwell and associates (3) demonstrated by catheterization techniques that there was a decrease in the coronary blood flow and cardiac efficiency associated with an increase in myocardial oxygen extraction after endotoxin. There was, however, no significant change in the calculated resistance to flow through the coronary vascular bed.

This paper reports changes in resistance to flow through the coronary vascular bed of the dog produced by local administration of the endotoxin of Salmonella typhosa 0901. Resistance was calculated from measurement of coronary perfusion pressure with the rate of blood flow to the coronary vascular bed held constant. The heart was beating but performing no external work.

\section{MATERIALS AND METHODS}

The study included a total of 20 mongrel dogs ranging in weight from 10 to $18 \mathrm{~kg}$. The animals were anesthetized with sodium pentobarbital (35 $\mathrm{mg}$ per $\mathrm{kg}$ ), and artificially ventilated through a tracheal cannula. The heart was exposed through the right fourth intercostal space. Heparin sodium ( $5 \mathrm{mg}$ per $\mathrm{kg}$ ) was injected intravenously and plastic cannulae were intro-

* Reported in part (Clin. Res. 1961, 9, 14). duced into the superior and inferior venae cavae by way of the right atrium (Figure 1). A rotating disc oxygenator, ${ }^{1}$ blood heat exchanger, ${ }^{2}$ and blood pump ${ }^{3}$ were interposed between the cannulae and the left femoral artery, and the body was perfused with oxygenated blood at $37^{\circ} \mathrm{C}$, at the rate of 80 to $90 \mathrm{ml}$ per $\mathrm{kg}$ per minute. At this point in the procedure positive-pressure respiration was terminated. Coronary venous blood was collected from the right side of the heart with a cannula threaded through the tricuspid valve and this blood was returned to the venous limb of the perfusion circuit. Left heart blood (from arterioluminal, thebesian, and bronchial vessels) was collected with another cannula inserted into the left atrium and left ventricle through a superior pulmonary vein. The flow from this cannula, usually less than $10 \mathrm{ml}$ per minute, was collected and returned to the venous limb of the perfusion circuit.

The coronary vascular bed was perfused at a constant flow rate with a second pump ${ }^{4}$ interposed between the right femoral artery and the ascending aorta (Figure 1). Flow rates were adjusted to produce mean pressures ranging from 72 to $130 \mathrm{~mm} \mathrm{Hg}$. At these pressures, covering the normal physiological range, flows varied from 72 to $153 \mathrm{ml}$ per minute. After setting the pump in motion, the aorta and pulmonary artery were cross clamped approximately $3 \mathrm{~cm}$ from the heart. ${ }^{5}$ This diverted the output of the pump through the entire coronary vascular bed. Hence, coronary perfusion was never interrupted. Perfusion pressure was measured with a resistance-wire pressure transducer. A needle in the external carotid artery measured systemic arterial pressure. The electrocardiogram was recorded throughout the experiment.

In 10 dogs, $0.6 \mathrm{mg}$ per $\mathrm{kg}$ of purified lipopolysaccharide (endotoxin) from S. typhosa $0901^{6}$ was injected in one bolus of fluid, usually less than $2 \mathrm{ml}$, into the coronary

${ }^{1}$ Kay-Cross disc oxygenator, Pemco Inc., Cleveland, Ohio.

2 Ward Laboratories, Durham, N. C.

3 Model T-65, Sigmamotor Inc., Middleport, N. Y.

4 Sigmamotor pump, model T-6. The pump was independent of pressure over the ranges encountered and was precalibrated to deliver 10 different rates of flow.

5 Postmortem tests showed the aortic valves to be competent to pressures in excess of those encountered.

${ }^{6}$ Bacto lipopolysaccharide, Difco Laboratories, Detroit, Mich. 
perfusion circuit. Coronary perfusion pressure and systemic arterial pressure were monitored over the succeeding 30 minutes with a two-channel direct-writing recorder. ${ }^{7}$ In a second series of $10 \mathrm{dogs}, 1 \mathrm{ml}$ of pyrogenfree water was injected into the coronary perfusion circuit and pressures were likewise recorded for the subsequent 30 -minute period.

In 5 of the 10 experimental animals, coronary arterial and venous blood samples were simultaneously withdrawn from the coronary perfusion circuit just proximal to the aorta and from the cannula inserted into the right heart, respectively, before and 30 minutes after endotoxin. These blood samples were analyzed for oxygen and carbon dioxide content, serum sodium and potassium concentrations, hematocrit and hemoglobin concentration, by the Van Slyke manometric method, flame photometry, microcapillary centrifugation, and photometric method, respectively.

Since vena caval and right heart pressures remained atmospheric, the resistance to flow through the coronary vascular bed and systemic circulation was calculated by dividing perfusion pressure by the rate of blood flow

${ }^{7}$ Model 60, Twin-Viso, Sanborn Co., Waltham, Mass. and was expressed as millimeters of mercury per milliliter per minute.

The proportion of time spent by the ventricles in systole was estimated by the following formula:

per cent of time spent in systole

$$
=\frac{Q T \text { interval } \times \text { no. beats } / \mathrm{min} \times 100}{60}
$$

At the conclusion of the experiments the animals were sacrificed and subjected to gross and microscopic pathological examination.

\section{RESULTS}

Coronary arterial pressure and resistance. There was no significant change in the coronary arterial pressure and resistance in the control animals given pyrogen-free water (Figure 2). After the injection of endotoxin there was a progressive decrease in the mean average coronary arterial resistance (Figure 2). Ten minutes after endotoxin arterial pressure had decreased in six dogs,

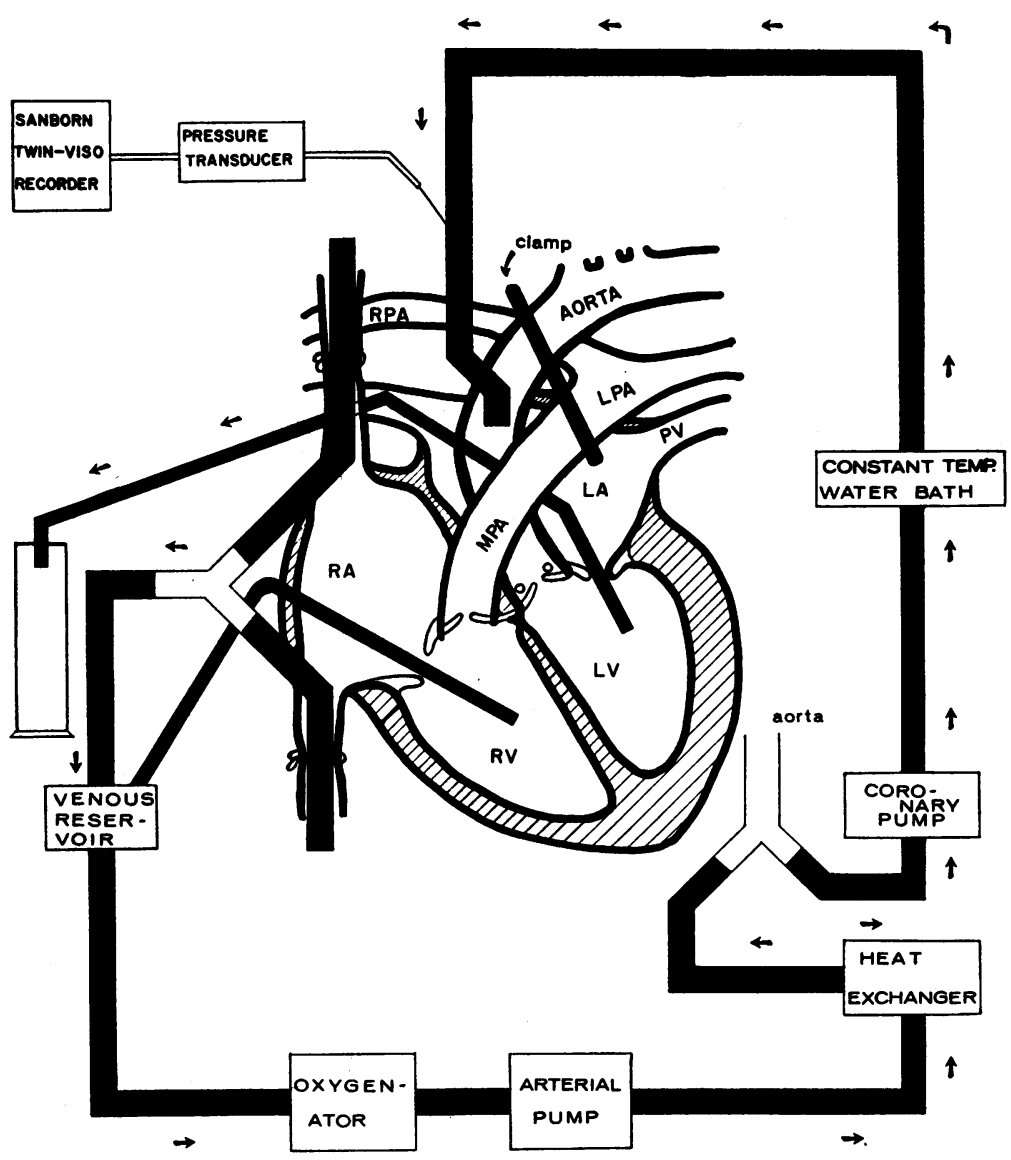

Fig. 1. Schematic diagram of the Cardiopulmonary bypass and CORONARY PERFUSION SYSTEMS. 

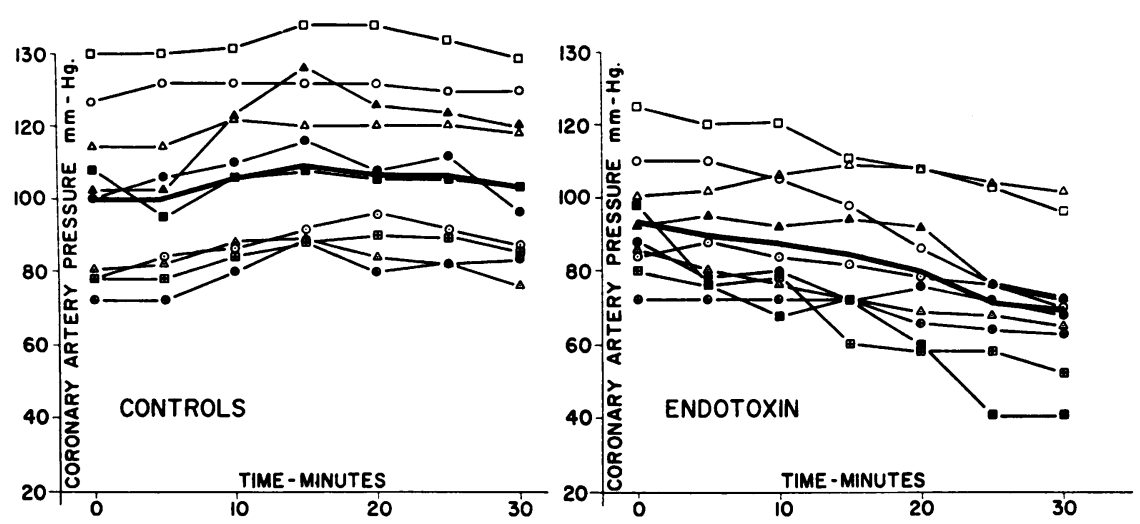

Fig. 2. Left: The efFECT OF 1 ML OF PYROGEN-FreE WATER ON THE CORONARY VASCULAR PRESSURE IN 10 CONTROL ANIMALS. Heavy line represents mean pressure. Coronary blood flow (average) $102 \mathrm{ml}$ per minute.

RIgHT: THE EFfeCt of $S$. typhosa ENDOTOXIN ( 0.6 MG PER KG) ON THE CORONARY vasCUlar PRESSURE IN 10 eXPERIMENTAL animals. Heavy line represents mean pressure. Coronary blood flow (average) $98 \mathrm{ml}$ per minute.

increased in one, and remained unchanged in three. During the final 20 minutes of the experiment coronary arterial pressure progressively decreased in nine of the ten dogs treated with endotoxin. The average arterial resistance prior to the administration of endotoxin was $0.95 \mathrm{~mm} \mathrm{Hg}$ per $\mathrm{ml}$ per minute, and resistance values at $5,10,15$, 20,25 , and 30 minutes after endotoxin were 0.91 , $0.89,0.86,0.81,0.75$, and $0.71 \mathrm{~mm} \mathrm{Hg}$ per $\mathrm{ml}$ per minute, respectively. The average resistance at 30 minutes was 25 per cent less than the average control value $(\mathrm{p}<0.01)$.

Systemic arterial pressure and resistance. There was no change in the systemic arterial pressure or calculated resistance in the control animals given pyrogen-free water (Figure 3). Systemic arterial pressure decreased in nine dogs and remained essentially unchanged in one after administration of endotoxin (Figure 3 ). The average control pressure was $65 \mathrm{~mm} \mathrm{Hg} ; 30$ minutes after endotoxin the pressure had fallen to an average of $47 \mathrm{~mm} \mathrm{Hg}$. This represented a 29 per cent decrease in total peripheral resistance $(p<0.01)$. The initial systemic arterial pressures were lower than normal. This was primarily due to the inability of the pump-oxygenator to deliver sufficient flows to maintain higher pressures in dogs of this size. Calculated total peripheral resistances, however, were within the normal physiological range.

Electrocardiographic changes. The effect of endotoxin upon heart rate and QT interval were of importance because they permitted an inference to be made regarding coronary vascular transmural pressure. Using the QT interval and heart rate it was found that there was no significant difference in the percentage of time the ventricles spent in systole (Table I). The electrocardiograms of those animals given endotoxin revealed nonspecific $\mathrm{T}$-wave abnormalities and premature ventricular contractions. Two dogs developed complete heart block concomitantly with intrapleural hemorrhage. Another animal developed intermittent runs of various types of intraventricular conduction defects.

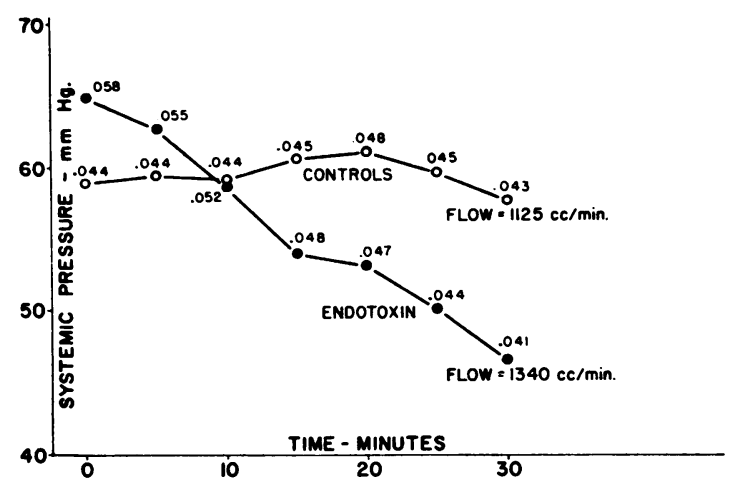

Fig. 3. Systemic vascular pressure changes in 10 EXPERIMENTAL ANIMALS AFTER ADMINISTRATION OF $S$. typhosa ENDOTOXIN ( 0.6 MG PER KG) AND IN 10 CONTROL ANIMALS AFTER ADMINISTRATION OF 1 ML OF PYROGENFREE WATER. Numbers represent calculated values for total peripheral resistance. 
TABLE I

The effect of intracoronary injection of endotoxin and pyrogen-free water on the percentage of time spent by the ventricles in systole*

\begin{tabular}{|c|c|c|c|c|c|c|c|c|c|c|}
\hline \multirow[b]{3}{*}{ Dog no. } & \multicolumn{5}{|c|}{ Dogs given pyrogen-free water } & \multicolumn{5}{|c|}{ Dogs given endoxin } \\
\hline & \multirow{2}{*}{$\begin{array}{l}\text { Coronary } \\
\text { flow }\end{array}$} & \multicolumn{2}{|c|}{ Heart rate at } & \multicolumn{2}{|c|}{$\begin{array}{l}\text { Time in } \\
\text { systole at }\end{array}$} & \multirow{2}{*}{$\begin{array}{l}\text { Coronary } \\
\text { flow }\end{array}$} & \multicolumn{2}{|c|}{ Heart rate at } & \multicolumn{2}{|c|}{$\begin{array}{l}\text { Time in } \\
\text { systole at }\end{array}$} \\
\hline & & $0 \mathrm{~min}$ & $30 \mathrm{~min}$ & $0 \mathrm{~min}$ & $30 \mathrm{~min}$ & & $0 \mathrm{~min}$ & $30 \mathrm{~min}$ & $0 \mathrm{~min}$ & $30 \mathrm{~min}$ \\
\hline & $m l / \min$ & & & $\%$ & $\%$ & $m l / \min$ & & & $\%$ & $\%$ \\
\hline 1 & 95 & 160 & 160 & 69 & 67 & 125 & 135 & 140 & 56 & 51 \\
\hline 2 & 95 & 130 & 140 & 74 & 70 & 95 & 140 & 140 & 56 & 56 \\
\hline 3 & 153 & 120 & 130 & 40 & 39 & 123 & 140 & 130 & 65 & 68 \\
\hline 4 & 72 & 150 & 100 & 45 & 46 & 95 & 120 & 200 & 40 & 46 \\
\hline 5 & 123 & 80 & 65 & 43 & 43 & 72 & 140 & 140 & 51 & 51 \\
\hline 6 & 153 & 120 & 130 & 56 & 56 & 123 & 140 . & 70 & 51 & 39 \\
\hline 7 & 75 & 140 & 135 & 65 & 67 & 123 & 160 & 160 & 64 & 64 \\
\hline 8 & 75 & 100 & 80 & 53 & 53 & 100 & 107 & 55 & 43 & 32 \\
\hline 9 & 100 & 120 & 130 & 48 & 47 & 50 & 165 & 155 & 69 & 72 \\
\hline 10 & 75 & 140 & 100 & 65 & 66 & 75 & 140 & 130 & 70 & 72 \\
\hline Average & 102 & 126 & 117 & 56 & 55 & 98 & 138 & 132 & 56 & 55 \\
\hline
\end{tabular}

* Calculation $:$ per cent of time spent in systole $=(Q T$ interval $\times$ heart rate $\times 100) / 60$.

Myocardial metabolism. There were no significant changes in arterial and venous hematocrit, in the concentrations of sodium and potassium, and in hemoglobin after endotoxin. The A-V difference for both oxygen and carbon dioxide increased slightly ( 0.8 and 1.8 vol per cent, respectively) but neither increase was statistically significant (Table II).

Postmortem examinations. Free blood was found at necropsy in all body cavities of animals treated with endotoxin. There was passive congestion in the liver and spleen. The mucous membranes of the gall bladder, stomach, and small intestine were edematous and hemorrhagic. Omental vessels were markedly dilated. Glandular tissues, including the pancreas, adrenals, and testes were hemorrhagic and congested. There were areas of hemorrhage and petechiae over the surface of the heart. The areas of hemorrhage were more extensive in the three experimental animals that developed heart blocks or intraventricular conduction defects. There were no gross or microscopic changes in the major coronary vessels. Microscopic examination indicated that the myocardial bleeding in the experimental animals originated from damaged capillaries. There were no-abnormalities of these types found on examination of animals injected with pyrogen-free water.

\section{DISCUSSION}

These studies show that the injection of the endotoxin of $S$. typhosa 0901 into the coronary vascular bed of the nonworking dog heart perfused at a constant flow results in a progressive decrease

TABLE II

Coronary oxygen consumption, carbon dioxide production, and resistance changes in dogs treated with Salmonella typhosa endotoxin

\begin{tabular}{|c|c|c|c|c|c|c|c|c|c|c|}
\hline \multirow[b]{2}{*}{ Dog no. } & \multirow{2}{*}{$\begin{array}{c}\text { Coronary } \\
\text { blood } \\
\text { flow }\end{array}$} & \multicolumn{3}{|c|}{ A-V oxygen* } & \multicolumn{3}{|c|}{ A-V carbon dioxide* } & \multicolumn{3}{|c|}{ Coronary vasc. resistance } \\
\hline & & Control & Exper.† & Diff. & Control & Exper.† & Diff. & Control & Exper.† & Change \\
\hline & $m l / \min$ & \multicolumn{2}{|c|}{ vol \% } & & \multicolumn{2}{|c|}{ vol \% } & & \multicolumn{2}{|c|}{$m m \mathrm{Hg} / \mathrm{ml} / \mathrm{min}$} & $\%$ \\
\hline 4 & 125 & 9.9 & 9.8 & -0.1 & 10.1 & 10.9 & +0.8 & 0.64 & 0.42 & -34 \\
\hline 5 & 95 & 7.0 & 7.3 & 0.3 & 6.4 & 6.6 & 0.2 & 0.88 & 0.74 & -16 \\
\hline 6 & 123 & 8.9 & 9.4 & 0.5 & 3.0 & 5.3 & 2.3 & 0.70 & 0.55 & -21 \\
\hline 7 & 95 & 2.5 & 4.0 & 1.5 & 1.7 & 6.8 & 5.1 & 1.01 & 0.42 & -58 \\
\hline 8 & 72 & 6.6 & 8.2 & 1.6 & 5.2 & 6.0 & 0.8 & 1.73 & 1.33 & -23 \\
\hline Average & 102 & 7.0 & 7.8 & 0.8 & 5.3 & 7.1 & 1.8 & 0.99 & 0.69 & -30 \\
\hline
\end{tabular}

* Duplicate samples (average).

$\dagger$ Thirty minutes after endotoxin. 
in coronary vascular resistance. This resistance decrease probably results from active vasodilatation due either to a direct effect of the endotoxin on vascular smooth muscle or to an indirect effect through some remote action of the endotoxin. In view of the studies of Hinshaw, Kuida, Gilbert and Visscher (4) it seems more likely that the effect of endotoxin is an indirect one.

A decrease in vascular resistance can be due either to vasodilatation or to a decrease in blood viscosity. However, since hematocrit and temperature remained unchanged throughout the experiments, resistance changes due to viscosity seem unlikely. It is highly improbable that the observed resistance changes were due to the effects of viscosity as influenced by the non-Newtonian character of blood, since both pressures and flow rates were within physiological limits (5).

Since there was no significant decrease in the proportion of time spent by the ventricles in systole (calculated from the QT interval and heart rate), it may be inferred that the extraluminal intra-myocardial pressure did not change. With no change in the extraluminal pressure the observed decrease in resistance must have resulted from active vasodilatation. Endotoxin, therefore, has an effect on the coronary vascular bed. Even though the amount of endotoxin given was less than that used in previous studies it is likely, because the endotoxin was injected directly into the coronary arteries, that the concentration achieved in the myocardium was higher.

Gilbert (2) suggests that the effect of endotoxin on resistances within individual vascular beds may be more important than its over-all effect on the total peripheral resistance. Studies have been reported on several vascular beds including the liver (6), intestine (7), kidney (8), and forelimb (9, 10). These studies indicate that there are two phases of the vascular response to endotoxin-an early, transitory phase of increased resistance and a longer phase of lowered resistance. Contrary to these studies, we were unable to demonstrate an increase in vascular resistance in the early phase. There was a progressive decrease in average coronary vascular resistance over the entire $30 \mathrm{~min}$ utes of the experiment. Whether the decreased resistance was due to a direct action of the endotoxin on the vascular bed, a decrease in vasomotor tone, or secondary to a release of vasoactive substances could not be determined during these experiments. A previous study reported from this laboratory (11) has shown that slight increases in local serum potassium actively dilate the coronary vascular bed of the dog. There was, however, no detectable change in serum potassium following endotoxin in this study.

It has been suggested $(6,12)$ that hypotension induced by endotoxin is primarily brought about by a diminished venous return and that calculated total peripheral resistance may even rise after the administration of endotoxin (13). Gilbert and Schiller (14), however, reported a decrease in total peripheral resistance; and Hinshaw and associates (15), have demonstrated a significant fall in total peripheral resistance in eviscerated and noneviscerated dogs after the administration of endotoxin. Utilizing a similar technique, the 29 per cent fall in total peripheral resistance demonstrated in our experiments is in close agreement with the 23 per cent reduction in total peripheral resistance reported by Hinshaw and co-workers even though our initial pressures were lower. In both studies control animals demonstrated no significant change in total peripheral resistance. The progressive decrease in the blood level in our oxygenator during studies involving the use of endotoxin indicated that there was a significant amount of vascular pooling. This decrease in blood level may have been due in part to free bleeding; however, it occurred within 12 minutes after endotoxin and before any observable hemorrhage. These results indicate that hypotension induced by endotoxin may be brought about both by a peripheral venous pooling of blood with a consequent diminished return to the heart, and by a decrease in arteriolar tone.

\section{SUMMARY AND CONCLUSIONS}

The effects of endotoxin on total peripheral resistance and on coronary vascular resistance of the beating, nonworking dog heart were studied during cardiopulmonary bypass. The administration of $0.6 \mathrm{mg}$ per $\mathrm{kg}$ of Salmonella typhosa endotoxin directly into the coronary arteries of dogs resulted in a progressive decrease in coronary vascular resistance and total peripheral resistance, which appeared to be due to active vasodilatation. 


\section{ACKNOWLEDGMENT}

The authors are grateful to Drs. Thomas R. A. Davis, Francis J. Haddy, Robert A. Hardin and Robert P. Gilbert for valuable assistance and suggestions in the preparation of this paper.

\section{REFERENCES}

1. Thomas, L. The physiological disturbance produced by endotoxins. Ann. Rev. Physiol. 1954, 16, 467.

2. Gilbert, R. P. Mechanisms of the hemodynamic effects of endotoxin. Physiol. Rev. 1960, 40, 245.

3. Maxwell, G. M., Castillo, C. A., Crumpton, C. W., Afonso, S., Clifford, J. E., and Rowe, G. G. The effect of the endotoxin (Serratia marcescens) upon the systemic, pulmonary, and coronary hemodynamics and metabolism of the intact dog. J. Lab. clin. Med. 1960, 56, 38.

4. Hinshaw, L. B., Kuida, H., Gilbert, R. P., and Visscher, M. B. Influence of perfusate characteristics on pulmonary vascular response to endotoxin. Amer. J. Physiol. 1957, 191, 293.

5. Haynes, R. H., and Burton, A. C. Role of nonNewtonian behavior of blood in hemodynamics. Amer. J. Physiol. 1959, 197, 943.

6. MacLean, L. D., Weil, M. H., Spink, W. W., and Visscher, M. B. Canine intestinal and liver weight changes induced by $E$. coli endotoxin. Proc. Soc. exp. Biol. (N. Y.) 1956, 92, 602.
7. Lillehei, R. C., and MacLean, L. D. The intestinal factor in irreversible endotoxin shock. Ann. Surg. 1958, 148, 513.

8. Hinshaw, L. B., and Bradley, G. M. Alterations in kidney weight produced by Escherichia coli endotoxin. Amer. J. Physiol. 1957, 189, 329.

9. Gilbert, R. P., and Gordon, P. Peripheral vascular reactions in experimental shock due to endotoxin. Clin. Res. Proc. 1956, 4, 110.

10. Vargas, R., and Beck, L. Effect of endotoxins on vascular reactivity. Fed. Proc. 1957, 16, 342.

11. Frohlich, E. D., Scott, J. B., Hardin, R. A., and Haddy, F. J. Effect of cations on coronary vascular resistance. Clin. Res. 1961, 9, 139.

12. MacLean, L. D., and Weil, M. H. Hypotension (shock) in dogs produced by Escherichia coli endotoxin. Circulat. Res. 1956, 4, 546.

13. Weil, M. H., MacLean, L. D., Visscher, M. B., and Spink, W. W. Studies on the circulatory changes in the dog produced by endotoxin from gram-negative microorganisms. J. clin. Invest. 1956, 35, 1191.

14. Gilbert, R. P., and Schiller, I. Endotoxin shock in the primate (abstract). J. Lab. clin. Med. 1960, $56,818$.

15. Hinshaw, L. B., Gilbert, R. P., Kuida, H., and Visscher, M. B. Peripheral resistance changes and blood pooling after endotoxin in eviscerated dogs. Amer. J. Physiol. 1958, 195, 631. 